Ulrich Preuss Stephen J. Ralston Gisli Baldursson Bruno Falissard Maria J. Lorenzo Rob Rodrigues Pereira Laurens Vlasveld David Coghill ADORE Study Group ${ }^{\star}$

\section{Study design, baseline patient characteristics and intervention in a cross-cultural framework: results from the ADORE study}

Dr. Dr. U. Preuss (西)

Head of Dept. of Research and Education Dept. of Child and Adolescent Psychiatry Bern University

Effingerstrasse 12

3011 Bern, Switzerland

Tel.: +41-31633/41-41

Fax: + 41-31633/41-91

E-Mail: Ulrich.preuss@kjp.unibe.ch

S. J. Ralston

Employed by Eli Lilly and Company at

the time the research was performed

G. Baldursson

Landspitali University Hospital

Dept. of Child and Adolescent Psychiatry

Reykjavik, Iceland

B. Falissard

INSERM U669

Université Paris-Sud

Paris, France

M. J. Lorenzo

Eli Lilly and Company

Lilly Research Centre

Windlesham, Surrey, UK

R. Rodrigues Pereira

Medical Centre Rijnmond South

Dept. of Paediatrics

Rotterdam, The Netherlands

L. Vlasveld

Reinier de Graaf Gasthuis

Afdeling kindergeneeskunde

Delft, The Netherlands

D. Coghill

Section of Psychiatry

Division of Pathology and Neuroscience

University of Dundee, Scotland, UK
* Members of the Adore Study Group G Baldursson, D Coghill, P Curatolo, S Dalsgaard, M Döpfner, B Falissard, A Hervas, MF Le Heuzey, TS Nøvik, RR Pereira, U Preuss, S Ralston, P Rasmussen, AW Riley, A Rothenberger, G Spiel, HC Steinhausen, L Vlasveld

Abstract Objective To describe the methodology and to present the baseline findings of the Attention-deficit/hyperactivity Disorder Observational Research in Europe (ADORE) study, the primary objective of which is to describe the relationship between treatment regimen prescribed and quality of life of children with ADHD in actual practice. Methods In this 2-year prospective observational study, data on diagnosis, prescribed treatment and outcomes of ADHD were collected at seven time points by paediatricians and child psychiatrists on 1,573 children recruited in 10 European countries. The data presented here from the $1,478 \mathrm{pa}$ tients included in the analyses describe the baseline condition, initial treatment regimen prescribed and quality of life of families with children with ADHD. Results Patients had a mean age of 9.0 years (SD 2.5) and $84 \%$ were male. Physicians diagnoses were made using
DSM-IV (43\%), ICD-10 (32\%) and both DSM-IV and ICD-10 (12\%). Mean age of awareness of a problem was 5.1 years, suggesting an average delay of approximately 4 years between awareness and diagnosis of ADHD. Baseline ADHD rating scale scores (physicianrated) indicated moderate to severe ADHD. Parent-rated SDQ scores were in agreement and suggested significant levels of co-existing problems. CGI-S, CGAS and CHIPCE scores also indicated significant impairment. Patients were offered the following treatments after the initial assessment: pharmacotherapy (25\%), psychotherapy (19\%), combination of pharmacotherapy and psychotherapy (25\%), other therapy (10\%) and no treatment (21\%). Conclusion The ADORE study shows that ADHD is similarly recognised across 10 European countries and that the children are significantly impaired across a wide range of domains. In this respect, they resemble children described in previous ADHD samples.

Key words ADHD - children Europe - quality of life symptoms 


\section{Abbreviations}

\begin{tabular}{|c|c|}
\hline ADHD & $\begin{array}{l}\text { Attention-Deficit/Hyperactivity Disor- } \\
\text { der }\end{array}$ \\
\hline ADORE & $\begin{array}{l}\text { Attention-deficit/hyperactivity Disor- } \\
\text { der Observational Research in Europe }\end{array}$ \\
\hline ADHD-RS-IV & ADHD Rating Scale-IV \\
\hline $\mathrm{CD}$ & Conduct Disorder \\
\hline CHIP-CE & $\begin{array}{l}\text { Child Health and Illness Profile - Child } \\
\text { Edition }\end{array}$ \\
\hline CGAS & Children's Global Assessment Scale \\
\hline CGI-S & $\begin{array}{l}\text { Clinical Global Impression-Severity } \\
\text { scale }\end{array}$ \\
\hline FSI & Family Strain Index \\
\hline HD & Hyperkinetic Disorder \\
\hline HRQoL & Health-Related Quality of Life \\
\hline ODD & Oppositional Defiant Disorder \\
\hline SDQ & $\begin{array}{l}\text { Strengths and Difficulties Question- } \\
\text { naire }\end{array}$ \\
\hline
\end{tabular}

\section{Introduction}

Attention-deficit/hyperactivity disorder (ADHD) is a common neurobiological disorder in children that is characterised by the core symptoms of developmentally inappropriate levels of inattention, hyperactivity and impulsivity. Diagnosis is made on the basis of observational data and a detailed clinical history, which is used to assess whether the patient meets diagnostic criteria. In Europe, there are varied approaches to the diagnosis of ADHD, with both the DSM-IV criteria of the American Psychiatric Association [1] and the ICD-10 criteria for hyperkinetic disorder (HD) of the World Health Organisation [42] being used. According to the DSM-IV criteria, symptoms of inattention and/or hyperactivityimpulsivity must persist for at least 6 months, be present before the age of 7 years, cause impairment in two or more settings (e.g. at school and at home), and there must be clear evidence of clinically important impairment in social, academic or occupational functioning. The ICD-10 criteria for HD is similar to the DSM-IV ADHD-combined type requiring symptoms of inattention, hyperactivity and impulsiveness to all be present, pervasive and result in functional impairments. Thus, the ICD-10 criteria select a smaller subgroup of children with more severe symptoms than those identified by the DSM-IV criteria [41].

Estimates of the prevalence of ADHD vary depending on the diagnostic criteria used within a study. However, there is general agreement that the prevalence of DSMIV-defined ADHD is between $5 \%$ and $8 \%$, and that of ICD-10-defined HD is around $1.5 \%$ [41]. Although ADHD is diagnosed in many European countries, the rates of diagnosis are much lower than those reported in the United States (US) and it is recognised that, in gen- eral, ADHD is under-diagnosed and under-treated by clinicians across Europe. Data from the United Kingdom (UK) and the Netherlands suggest low rates of referral and diagnosis, and scepticism of medical professionals regarding the disorder (see [30]). The full extent to which ADHD varies across European countries has not been systematically studied. Whilst there will be many similarities between children with ADHD across these countries, it is suspected that the differing funding patterns, traditions and historical development of child and adolescent mental health services across Europe will result in large variations in the rate of ADHD diagnosis and in clinical practice.

ADHD rarely presents as an isolated difficulty, but frequently co-exists with other conditions such as oppositional defiant disorder (ODD), conduct disorder (CD), learning disorders, anxiety, depression, epilepsy, tic disorders and Tourette's syndrome $[4,29]$. The presence of such co-existing conditions can complicate the diagnosis of ADHD and contribute to the severity of the hyperactive/inattentive/impulsive symptoms [40]. ADHD also often results in significant academic, social and emotional problems both at home and school. Children with severe ADHD often have low self-esteem, develop emotional and social relationship problems, and frequently under-achieve at school. Moreover, ADHD is a chronic disorder that often persists into adolescence and adulthood, and is associated with continued impairment [12]. ADHD impacts on the daily lives of not only the affected child, but also their family and society in general. ADHD has been associated with disturbances in the family, such as strain in the child-parent relationship, parental marital dissatisfaction, greater conflict between parents, and high levels of parental stress. These difficulties can be further compounded by the economic stresses associated with parental work disruptions and medical care costs [2].

The full burden of ADHD in Europe has not been established, particularly the impact of the disorder and its treatment on patient quality of life in actual practice. A recently reported prospective case-control study conducted in Spain found that untreated children with newly diagnosed ADHD had a worse quality of life than healthy children or children with newly diagnosed asthma [10]. Not surprisingly, the quality of life among children with ADHD worsened as the severity of ADHD symptoms increased and with the presence of co-morbid psychiatric disorders [21]. At least one randomised controlled clinical trial has demonstrated quality of life improvements upon medication treatment [28].

There is also a lack of information about the impact of ADHD on families, on healthcare utilisation and its costs in Europe. Most published studies have been conducted in the US and demonstrate a considerable economic burden on patients, families and the healthcare system [22]. 
Since there is such a paucity of information about how ADHD is diagnosed and treated in the naturalistic setting, the Attention-Deficit/Hyperactivity Disorder Observational Research in Europe (ADORE) study was designed as a 24-month, pan-European, prospective, non-interventional study to evaluate diagnosis, treatment patterns and health outcomes associated with ADHD [30]. The primary objective of the study is to describe the relationship between treatment regimen prescribed and quality of life of children with ADHD in actual practice, over a 2-year period. The secondary objectives of the ADORE study are to describe: how treatment regimens are modified over a 2-year period; the relationship between diagnosis, actual practice and ratings of ADHD symptom severity; the relationship between treatment regimen and the severity of ADHD symptoms and co-existing problems; and the relationship between treatment regimen prescribed and physicians with different medical specialities. This paper describes the design of the ADORE study and outlines the baseline characteristics of the study population.

\section{Methods}

\section{ADORE study design and population}

This ongoing, 2-year, prospective, non-interventional, observational study is being conducted in 10 European countries: Austria, Denmark, France, Germany, Iceland, Italy, the Netherlands, Norway, Switzerland, and the UK. Patient recruitment commenced in June 2003 and was completed in December 2004. Each participating country had a maximum patient recruitment period of 6 months.

The treatment choice for patients enrolled in ADORE is at the full discretion of the participating physician and reflects the care patients receive under routine clinical circumstances.

Physicians participating in the study all have experience in the treatment of ADHD, hyperactive/inattentive/impulsive symptoms and associated problems. Across countries, such physicians may come from different medical specialities, including child psychiatrists and paediatricians. Before the study commenced, the different types of physicians who diagnose and treat ADHD in each participating country was defined, and efforts were made to recruit an equal-sized proportion of physicians from each of these medical specialities to participate in the study. There was no minimum number of patients per investigator.

Patients included in the study were required to be aged 6-18 years, with hyperactive/inattentive/impulsive symptoms, but no previous formal diagnosis of ADHD or HD. Patients with mental retardation, autism or schizophrenia, and those simultaneously participating in other studies that included treatment interventions and/or an investigational drug were excluded from the study.

The study was approved by local ethics committees or review boards in each participating country. Patient informed consent followed country regulations, with all patients or their parents providing at least verbal informed consent for the provision and collection of data regarding care and outcomes for the duration of the study (two years).

\section{Data collection}

\section{Schedule}

All data collection occurred during routine physician visits. The outpatient visit at which patients were enrolled served as the baseline data collection point (T1). Six subsequent data collection periods were defined over a 2-year period: the first return to physician between 1 week and 2 months (T2), and then at 3 months (T3), 6 months (T4), 12 months (T5), 18 months (T6) and 24 months (T7), with a defined data collection target interval range around these times as shown in Fig. 1. The first routine visit occurring within each time period served as the data collection point. The study protocol did not require data to be collected at every target time interval for a patient to remain in the study. Thus, if a routine visit was not scheduled during any specified time period, data were not collected.

\section{Data sources}

Data were collected from physicians and parents, with whichever parent who brought the child to the visit completing the parent forms. At each visit, they completed a 12-page form that took approximately $30 \mathrm{~min}$ utes to complete. The following broad areas of data were collected at each visit: patient demographics, functioning, clinical status, treatment, tolerability of and compliance with treatment, contacts with police and/or social services, bullying and/or truancy, health-related quality of life, and medical resource use. In addition, questions were asked at the baseline visit about the age of the child when parents first became aware of hyperactive/impulsive/inattentive symptoms, and the age of the child when treatment was first sought for these symptoms.

\section{Study measures}

\section{Physician reported measures}

The ADHD Rating Scale-IV-Parent version-Investigator completed (ADHD-RS-IV) was used at every visit to as- 


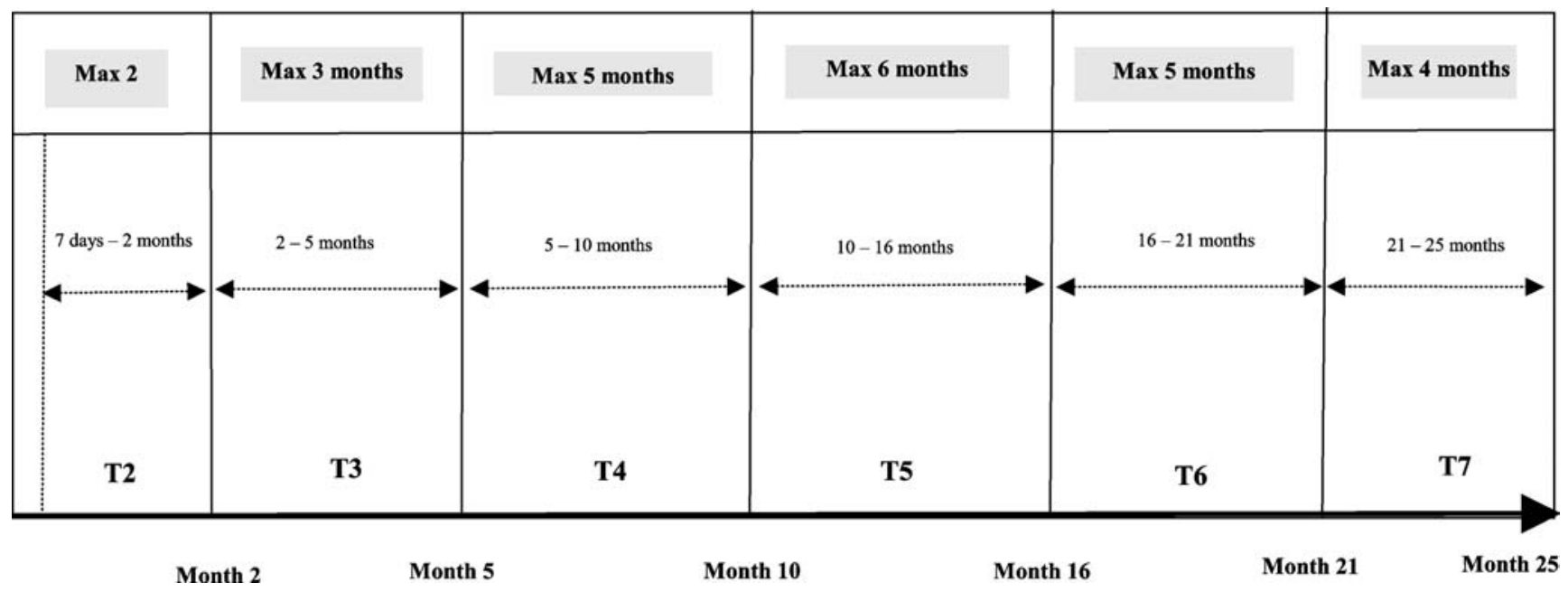

Fig. 1 Data collection schedule for the ADORE study

sess ADHD symptom severity [8]. The ADHD-RS-IV is derived directly from DSM-IV criteria, was adapted for all languages of participating countries and was validated within the ADORE sample [7]. Factor analyses gave evidence for the two expected subscales of the ADHD-RS-IV: Inattention and Hyperactivity-Impulsivity. Each of the 18 items in the scale is scored on a 4-point scale from $0=$ never or rarely (never) to $3=$ very often (severe).

The Children's Global Assessment Scale (CGAS) [37] and the Clinical Global Impression-Severity (CGI-S) scale [16] were used at each data collection point to assess the global health status of patients. For the CGAS, a score of $>70$ is generally accepted to indicate good overall functioning and a score of $<60$ indicates poor functioning that will generally require intervention (a score of $<60$ was used as the benchmark in the DSM-IV field trials to define the level below which significant impairment occurs and a clinical diagnosis is appropriate). The CGI-S is a 7-point scale ranging from $1=$ normal, not at all ill to $7=$ very severely ill. A score of 4 indicates moderately ill and a score of 5 indicates markedly ill.

The presence and severity of anxiety, depression, CD, and ODD symptoms was assessed using a scale based on the 7-point CGI-S scale and scored in the same way, with those scoring $\geq 4$ (moderately ill) being assessed as having a significant problem. Other co-existing problems, such as Tourette's syndrome, tics, co-ordination problems, learning disorders, bipolar disorder, psychosis, obsessive-compulsive disorder, asthma and epilepsy, were assessed as present, not present or unknown. The presence of additional health problems, such as sleep problems, decreased appetite, headache and abdominal pains was also assessed as: present and significantly interfering with functioning; present but not significantly interfering with functioning; not present; or unknown.
At each data collection point, physicians also recorded details of any treatment prescribed for ADHDrelated symptoms, including pharmacotherapy, psychotherapy and any other treatments. The name and daily dose of the pharmacotherapy prescribed were recorded. Physicians checked a box to indicate which, if any, psychotherapy/training was provided (including psychoeducation/counselling, cognitive behavioural therapy, family therapy, psychodynamic therapy) and indicated the number of sessions per month. Other treatments listed included educational interventions in school, speech therapy, occupational therapy, relaxational techniques, hypnosis, psychomotor/physiotherapy, EEG biofeedback, herb/homeopathy, diet exclusion and diet supplements. In addition, resource utilisation such as primary care physician visits, accident and emergency visits, and any other diagnostic tests performed were recorded. This information will be used in future analyses to describe the treatment patterns initiated by different physicians for different levels of ADHD symptom severity. Local published costs will be applied to this resource utilisation to estimate the direct costs of treating patients with ADHD.

\section{Parent reported measures}

Parent reported emotional and behavioural problems and functioning of patients was assessed using the Strengths and Difficulties Questionnaire (SDQ) [14]. The SDQ was developed from the well-established Rutter scales [36]. The properties of the SDQ have been well researched in various international studies that gave evidence for the good psychometric properties and factorial consistency of this scale $[15,35]$. The SDQ is completed by parents and consists of 25 items that refer to different emotions or behaviours of the child, with each 
item scored as $0=$ not true, $1=$ somewhat true, or $2=$ certainly true. The SDQ reports a total score and 5 subscale scores, with each subscale (emotional symptoms, conduct problems, hyperactivity/inattention, peer relationship problems and prosocial behaviour) consisting of 5 items each. Cut-off scores for the SDQ parent completed version are (according to the UK norms): total problems "borderline" 14-16, "abnormal" $\geq 17$; conduct problems "borderline" 3 ,"abnormal" $\geq 4$; hyperactivity "borderline" 6 , "abnormal" $\geq 7$; emotional symptoms "borderline" 4, "abnormal" $\geq 5$; peer problems "borderline" 3 , "abnormal" $>4$; and prosocial behaviour "borderline" 5 , "abnormal" $\leq 4$. The validity and reliability of the SDQ parent completed version was confirmed for the ADORE study population, as reported elsewhere in this supplement [3].

Health-related quality of life (HRQoL) was assessed at every data collection point using the parent report form of the Child Health and Illness Profile-Child Edition (CHIP-CE) $[32,33]$. The CHIP-CE is a reliable and well-validated instrument that measures overall HRQoL and, amongst other areas, allows assessment of patient mental health, self-esteem, general behaviour and involvement with family and peers. It consists of 76 items covering the five domains of Satisfaction, Comfort, Risk Avoidance, Resilience and Achievement. The validity and reliability of the parent report form of the CHIP-CE in this pan-European sample of children and adolescents with ADHD was confirmed, as reported elsewhere in this supplement [31]. Raw scores on the CHIP-CE are converted into standard scores based on a US control sample, such that a score of 50 is the mean for a healthy population and each 10 units indicates a change of one standard deviation from this mean.

The level of strain, stress and other reactions in families of a child with ADHD was also assessed using a brief 6-item questionnaire - the Family Strain Index (FSI) developed specifically for the study [34].

\section{Analysis}

Initial analyses of the ADORE study focus on describing the characteristics of the patients recruited to the study. All data are presented as summary descriptive statistics: means, standard deviations (SD) or percentages, as appropriate.

\section{Results}

\section{Patient characteristics and diagnosis}

Across the 10 participating countries, 244 investigators enrolled at least one patient. A total of 1,573 patients were enrolled in the study, with the number of patients enrolled in each country exceeding the enrolment target. Of the patients enrolled, $95(6 \%)$ were excluded from the analyses for the following reasons: methylphenidate (MPH) treatment taken prior to study $(n=61)$, outside age range $(n=11)$, enrolled in another clinical trial $(n=1)$ and failure to meet other inclusion/exclusion criteria $(n=22)$.

A total of 1,478 patients were included in the analysis at baseline; they had a mean age of 9.0 years (SD 2.5) and the majority of patients were male $(84 \%)$. The number of patients included in the baseline analysis of the ADORE study by country is summarised in Table 1, together with the patient demographics (age, gender), paid employment status of parents, family history of ADHD, patient age at first awareness of problems and patient age when treatment was first sought. The major-

Table 1 Sample descriptive data, employment status of parents, family history of ADHD and age of awareness of children's problems

\begin{tabular}{lclllllll}
\hline Country & $\begin{array}{l}\text { Patients analysed, } \\
\text { N (\% of sample) }\end{array}$ & $\begin{array}{l}\text { Mean age, } \\
\text { years (SD) }\end{array}$ & Male, \% & $\begin{array}{l}\text { Mother } \\
\text { working, \% }\end{array}$ & $\begin{array}{l}\text { Father } \\
\text { working, \% }\end{array}$ & $\begin{array}{l}\text { Family history } \\
\text { of ADHD, \% }\end{array}$ & $\begin{array}{l}\text { Mean age at first } \\
\text { awareness of problems, } \\
\text { years (SD) }\end{array}$ & $\begin{array}{l}\text { Mean age when first } \\
\text { sought treatment, } \\
\text { years (SD) }\end{array}$ \\
\hline Austria & $73(5)$ & $9.3(2.7)$ & 94 & 65 & 97 & 55 & $4.5(2.3)$ & $7.2(3.1)$ \\
Denmark & $32(2)$ & $9.2(2.1)$ & 91 & 87 & 86 & 62 & $4.3(2.4)$ & $5.5(2.4)$ \\
France & $241(16)$ & $8.8(2.2)$ & 88 & NC & NC & 50 & $5.2(2.7)$ & $7.5(2.7)$ \\
Germany & $434(29)$ & $8.7(2.1)$ & 79 & 64 & 94 & 69 & $5.0(2.5)$ & $7.0(2.3)$ \\
Iceland & $46(3)$ & $9.5(2.4)$ & 79 & 80 & 95 & 76 & $5.8(2.4)$ & $7.3(2.4)$ \\
Italy & $109(7)$ & $8.5(2.4)$ & 86 & 66 & 98 & 58 & $5.2(2.5)$ & $7.4(2.5)$ \\
Netherlands & $212(14)$ & $9.1(2.9)$ & 86 & 75 & 97 & 66 & $5.1(3.3)$ & $7.7(3.2)$ \\
Norway & $50(3)$ & $9.8(2.4)$ & 74 & 76 & 89 & 71 & $4.5(2.5)$ & $7.3(2.5)$ \\
Switzerland & $57(4)$ & $9.7(3.0)$ & 89 & 65 & 100 & 76 & $5.9(3.2)$ & $7.9(2.9)$ \\
UK & $223(15)$ & $9.3(2.7)$ & 86 & 52 & 80 & 64 & $5.3(3.0)$ & $7.6(3.1)$ \\
All & $1,478(100)$ & $9.0(2.5)$ & 84 & 66 & 93 & 64 & $5.1(2.7)$ & $7.3(2.8)$ \\
\hline
\end{tabular}

Data are presented as \% within country unless indicated otherwise. SD standard deviation, NC data not collected in France 
ity of patients were recruited in the German speaking countries (Germany, Austria and Switzerland); other major parts of the sample were from France, UK, the Netherlands and Italy. Most children lived with both biological parents $(66 \%)$, with most of the others either living with a single biological parent $(17 \%)$ or a biological parent and a step parent (11\%) (data not shown). In the majority of families, at least one parent had paid work. The figures on employment do not distinguish between those parents who are unemployed due to economic conditions or due to illness of the child and those who are voluntarily out of work.

For $64 \%$ of cases in all European countries, the information was given that at least one relative in the family of the child had a history of ADHD. However, the majority of mothers $(58 \%)$ and fathers $(76 \%)$ had no health problems recorded at baseline. Parental health problems were predominantly emotional and showed considerable variation between countries and parent gender, ranging from $7 \%$ in Iceland to $57 \%$ in Italy for mothers, and from $3 \%$ in Iceland to $30 \%$ in Italy for fathers. There were only a few guardians $(n=116)$ in the sample and the majority $(88 \%)$ had no health problems.

For the total study population, the mean age of the child at first awareness of problems was 5.1 years (SD 2.7) and the mean age when treatment was first sought was 7.3 years (SD 2.8), giving a delay of just over 2 years between first becoming aware of the problem and seeking treatment. As the mean age of the child at baseline when enrolled into the study was 9.0 years (SD 2.5), this means that it took approximately 4 years across all countries from first recognition of a behaviour problem to receiving a diagnosis of ADHD. The pattern was similar for each country except Denmark, where there was a younger age of first awareness of problems (mean 4.3 years) and first seeking treatment (mean 5.5 years), although age at enrolment (mean 9.2 years) was similar to that in other countries.

\section{ADHD diagnosis}

Across the European countries participating in the ADORE study (excluding France where clinicians opted not to answer this question), physicians reported that they had used formal diagnostic criteria to diagnose ADHD or HD in $92 \%$ of children in the study. A diagnosis of ADHD was made using DSM-IV criteria alone in $43 \%$ of patients and a diagnosis of HD using the ICD- 10 criteria alone in $32 \%$ of patients. There were notable differences between countries in the use of the DSM-IV and ICD-10 criteria. In the Netherlands, Italy and the UK, most cases of ADHD were diagnosed using the DSM-IV criteria $(82 \%, 69 \%$ and $57 \%$ respectively), whereas use of the ICD-10 criteria was preferred in the other countries. Both DSM-IV and ICD-10 criteria were used for $12 \%$ of patients, especially for patients in Iceland $(32 \%)$, Germany (18\%) and Italy (18\%).

Further examination of the criteria used for diagnosing ADHD (DSM-IV alone, ICD-10 alone, both DSM-IV and ICD-10) revealed no gender differences (data not shown). Across the participating countries (excluding France), $91 \%$ of girls and $93 \%$ of boys were given a diagnosis of ADHD using diagnostic criteria.

\section{Symptom and impairment levels at baseline}

For the total study population at baseline, the mean scores on the physician-rated scales were as follows: total ADHD-RS-IV score 35.8 (SD 9.2); overall CGI-S score 4.4 (SD 0.9); CGAS score 55.2 (SD 10.6). The mean SDQ total difficulties score was 20.4 (SD 6.0) and for the SDQ subscales, the mean scores were: conduct problems 4.5 (SD 2.3), hyperactivity-inattention 8.3 (SD 1.7), emotional symptoms 4.0 (SD 2.4), peer relationships problems 3.7 (SD 2.5), and prosocial behaviour 6.8 (SD 2.3). The mean scores for each of the CHIP-CE domains were considerably reduced compared with healthy population norms (mean 50.0, SD 10.0): Satisfaction 32.8 (SD 14.4), Comfort 42.5 (SD 10.6), Resilience 36.0 (SD 12.2), Risk Avoidance 29.9 (SD 13.6), and Achievement 30.3 (SD 10.6). For each of these rating scales, the scores were similar between countries (data not shown). Taken together, these results indicate a medium to high level of severity of illness among the ADORE study ADHD patients at baseline.

\section{Co-existing problems and somatic complaints}

The majority of patients ( $80 \%)$ had at least one co-existing problem (excluding asthma and epilepsy, which were present in $8 \%$ and $<1 \%$ of patients, respectively), and $51 \%$ of patients had two or more co-existing problems. The number (\%) of patients overall and within each country with co-existing problems are summarised in Table 2. The most common co-existing problems were learning disorders (56\%), CD and/or ODD (41\%), coordination problems $(33 \%)$, anxiety and/or depression $(18 \%)$ and tics and/or Tourette's ( $8 \%)$, although the rates of these disorders varied considerably between countries. Additionally, there were very low rates of coexisting obsessive compulsive disorder (2\%), bipolar disorder $(<1 \%)$ or psychosis $(<1 \%)$. More details on co-existing psychiatric problems in the ADORE sample at baseline are presented by Steinhausen et al. [39].

Sleep problems that were present and significantly interfering with patient's functioning or quality of life were reported in $14 \%$ of all patients. However, there were variations between countries, with sleep problems being present and interfering in less than $1 \%$ of patients 
Table 2 Co-existing problems identified by physician at baseline

\begin{tabular}{lccccc}
\hline Number (\%) patients with co-existing problem & & & \\
\hline Country & $\begin{array}{l}\text { Anxiety and/ } \\
\text { or Depression }\end{array}$ & CD and/or ODD & Tics/Tourettes & $\begin{array}{l}\text { Learning } \\
\text { Problems }\end{array}$ & $\begin{array}{l}\text { Coordination } \\
\text { Problems }\end{array}$ \\
\hline Austria & $4(6)$ & $22(32)$ & $5(7)$ & $33(52)$ & $22(33)$ \\
Denmark & $4(13)$ & $16(52)$ & $4(13)$ & $23(77)$ & $14(47)$ \\
France & $105(44)$ & $130(54)$ & $25(11)$ & $148(63)$ & $62(27)$ \\
Germany & $57(14)$ & $197(46)$ & $20(5)$ & $262(64)$ & $168(41)$ \\
Iceland & $9(20)$ & $16(34)$ & $12(26)$ & $20(44)$ & $15(33)$ \\
Italy & $18(17)$ & $28(26)$ & $4(4)$ & $41(41)$ & $10(9)$ \\
Netherlands & $27(13)$ & $75(36)$ & $22(10)$ & $113(55)$ & $63(30)$ \\
Norway & $7(15)$ & $18(37)$ & $7(15)$ & $17(46)$ & $18(41)$ \\
Switzerland & $8(15)$ & $9(16)$ & $2(4)$ & $21(42)$ & $20(38)$ \\
UK & $16(8)$ & $91(41)$ & $21(9)$ & $84(44)$ & $74(34)$ \\
All & $255(18)$ & $602(41)$ & $122(8)$ & $762(56)$ & $466(33)$ \\
\hline
\end{tabular}

Data are presented as number and \% of patients within each country. CD Conduct Disorder, ODD Oppositional Defiant Disorder in Italy up to $20 \%$ of patients in the Netherlands. Other somatic symptoms were present in a low proportion of patients at baseline: decreased appetite $(1 \%)$, headaches $(5 \%)$ and abdominal pains $(4 \%)$.

\section{Involvement in bullying}

Overall, parents reported to physicians that $38 \%$ of children with ADHD were involved in bullying; $15 \%$ as victims only, $14 \%$ as the bully only and $9 \%$ as a combination of victim and bully. Italy had the lowest proportion of patients involved in bullying $(22 \%)$ followed by Norway $(29 \%)$, Iceland $(26 \%)$, UK $(33 \%)$, Switzerland (34\%), Germany (35\%), Denmark (46\%), France (46\%), the Netherlands (48\%) and Austria (59\%).

\section{Treatment prescribed/proposed}

Pharmacotherapy was the leading choice of treatment prescribed/proposed at the baseline visit, being prescribed for $50 \%(734 / 1471)$ of patients with data available. Likewise, psychotherapy was prescribed for $44 \%$ $(655 / 1472)$ of patients and $43 \%(622 / 1436)$ were prescribed "other" therapy at the baseline visit. Looked at in a different way, $19 \%$ of patients were prescribed psychotherapy \pm "other" treatment, $25 \%$ pharmacotherapy \pm "other" therapy, $25 \%$ combined psychotherapy and psychotherapy \pm "other" therapy, $10 \%$ "other" therapy only and $21 \%$ were not prescribed treatment at this time. There were wide variations between countries in the types of treatment prescribed at baseline as shown in Table 3.

Table 3 Treatment prescribed or proposed at baseline visit, by country

\begin{tabular}{|c|c|c|c|c|c|}
\hline \multicolumn{6}{|c|}{$\%$ Patients within each country } \\
\hline Country & $\begin{array}{l}\text { Psychotherapy } \\
\pm \text { other therapy }\end{array}$ & $\begin{array}{l}\text { Combined psychotherapy, } \\
\text { pharmacotherapy } \pm \text { other therapy }\end{array}$ & $\begin{array}{l}\text { Pharmacotherapy } \\
\pm \text { other therapy }\end{array}$ & Other therapy only & None \\
\hline Austria $(\mathrm{N}=67)$ & 52 & 9 & 6 & 16 & 16 \\
\hline Denmark ( $N=32)$ & 19 & 3 & 38 & 22 & 19 \\
\hline France $(N=234)$ & 27 & 36 & 23 & 5 & 9 \\
\hline Germany (N=416) & 19 & 23 & 21 & 10 & 27 \\
\hline Iceland ( $\mathrm{N}=45)$ & 11 & 31 & 20 & 0 & 38 \\
\hline Italy $(\mathrm{N}=105)$ & 30 & 9 & 10 & 22 & 30 \\
\hline Netherlands $(\mathrm{N}=206)$ & 4 & 46 & 40 & 3 & 7 \\
\hline Norway $(N=49)$ & 14 & 14 & 12 & 16 & 43 \\
\hline Switzerland $(\mathrm{N}=53)$ & 23 & 38 & 17 & 8 & 15 \\
\hline UK $(N=221)$ & 11 & 11 & 38 & 17 & 23 \\
\hline All $(\mathrm{N}=1,428,100 \%)$ & $19(n=270)$ & $25(n=356)$ & $25(n=360)$ & $10(n=148)$ & $21(n=294)$ \\
\hline
\end{tabular}

Data missing for 50 patients 


\section{Discussion}

The ADORE study is not intended to provide a sophisticated comparison of the diagnosis and treatment patterns or epidemiological phenomena of ADHD in the participating European countries. Rather, its primary aim is to describe the real world population of children with newly diagnosed ADHD in Europe. Because of the heterogeneity of the sampling method, sample size, types of investigator and other uncontrolled variables, the data are not representative for each country and, therefore, do not allow for conclusive analysis of the differences between countries.

The baseline data are intended to describe the characteristics of the sample and serve as a reference from which the impact of treatment on the child's condition and well-being and that of their family can be judged as the study progresses. The data show the ADORE study population was young (mean age 9 years) and predominantly male ( $84 \%)$, consistent with previous large-scale studies of ADHD in children, such as the Multimodal Treatment study of children with ADHD [26]. The majority of children lived with their parents, both of whom were working in most cases. The lowest rate of mothers in paid employment was in the UK (52\%).

Although a formal diagnosis of ADHD or HD was not required, the majority of children enrolled into the study were given one of these diagnoses. Interestingly, although the ICD-10 is the standard instrument of classification for mental disorders in most European countries, the majority of investigators in the ADORE study used the DSM-IV criteria (developed and used in the US), either alone or together with the ICD-10 criteria, for diagnosing ADHD. This may be because these physicians are aware that the ICD-10 criteria selects a smaller group of children with all three symptoms of inattention, hyperactivity and impulsiveness, and does not distinguish the three subtypes of ADHD identified by the DSM-IV criteria (predominantly inattentive, predominantly hyperactive-impulsive, combined).

The time gap between first recognition of problems and assessment/diagnosis is striking. We observed approximately a 2-year difference between the age at first awareness of symptoms and the age at which treatment was first sought, and a further 2-year gap between age at which treatment was first sought and age at final diagnosis of ADHD. Importantly, this delay of approximately 4 years until ADHD diagnosis was seen in all participating countries, although awareness of problems and seeking treatment seemed to occur at a younger age in Denmark. This may be due to a higher awareness of ADHD in Denmark or could be an artefact caused by the low number of patients from this country participating in the study. There may be many reasons for the delay between first awareness of a problem and final diagnosis of $\mathrm{ADHD}$, including delays in the referral process and in processing referrals once they are made and a shortage of available well-trained staff to make the full assessment. Nevertheless, further research on the awarenessdiagnosis-treatment gap would be of considerable value as earlier diagnosis and treatment intervention may reduce the severity and burden of the disorder during the critical stage of a child's development.

One of the strengths of this study is its ability to describe the levels of impairment across a wide range of well-validated measures in a group of children who are treatment naïve with respect to their ADHD symptoms and who have been referred to child and adolescent psychiatric and paediatric services across Europe. At baseline, this group of children was found to have moderate to severe symptoms of ADHD and levels of impairment, together with significant levels of co-existing problems as assessed by both physicians (ADHD-RS-IV, CGI-S and CGAS) and parents (SDQ). The mean ADHD-RS-IV score (35.8) whilst relatively high is somewhat lower than that seen in recent clinical trials of ADHD medication, where scores were in the range of 37 to $41[24,25]$. The mean CGI-S score (4.4) suggests that most patients were rated as moderately or severely ill and the mean CGAS score (55.2) fell well below the cut-off for significant clinical impairment. The mean SDQ total difficulties score and subscale scores for conduct problems and hyperactivity-inattention were all within the abnormal range, those for emotional symptoms and peer problems were borderline, with only prosocial behaviour falling within the normal range. These clinical indicators of severity were accompanied by significantly impaired measures of quality of life assessed using CHIP-CE, which averaged two standard deviations below the expected scores for a healthy population. Recent studies measuring HRQoL with the Child Health Questionnaire found that ADHD impairs many aspects of a child's life; HRQoL was closely associated with clinical symptoms and became poorer as ADHD symptom severity increased [21, 23]. Taken together, these findings reinforce previous findings on the impact of ADHD and suggest that those children being referred to clinical services across Europe are indeed in need of treatment and support.

ADHD not only affects the child, but also has a significant impact on family functioning [18], although it is not clear how this varies among countries. In the ADORE study, the burden of ADHD on the family was reflected in the health problems experienced by parents, especially emotional problems, which affected up to half of mothers and up to one-quarter of fathers, depending on the country. An important consideration in the effective treatment of ADHD is how its affects the health and functioning of the entire family. Family stress and strain at baseline, assessed using the FSI, is reported elsewhere in this issue, together with an assessment of the reliability and factor structure of the questionnaire [34]. Although the FSI has not previously been standardised, it 
is anticipated that the scores obtained in the ADORE study will allow us to track the impact of treatment on family strain as the study progresses.

Consistent with previous findings [4], the majority of children in the ADORE study had one or more co-existing problems in addition to their clinically impairing ADHD symptoms. Learning disorders and behavioural problems, such as ODD and CD, were the most common co-existing problems in the ADORE study population, in agreement with previous reports in school-aged children with ADHD $[4,5,13,17]$. Co-ordination problems and emotional problems were also relatively common and occurred in this sample at similar rates to those reported in previous samples $[4,5,13,17]$.

Sleep disturbances are common in children with ADHD and have a reported prevalence of up to $50 \%$ [6]. Although $40 \%$ of children in the ADORE study were reported to have sleep problems, only $14 \%$ of children had sleep problems that were felt by their parents to significantly interfere with their functioning and quality of life. Interestingly, the rate of sleep problems varied between countries and was very low $(<1 \%)$ in Italy. The relationship between sleep and ADHD is complex and not well understood $[19,20,27]$. Sleep disturbance is an important symptom in unmedicated children with ADHD, but is also considered a frequent side effect of stimulant treatment [38].

Involvement in bullying also appears to be a considerable problem for children with ADHD in all the participating countries, confirming the widespread social problems faced by this group of children.

The baseline data from the ADORE study indicated that there may be differences between European countries in their approach to early ADHD treatment. Doctors in the Netherlands, UK and Denmark favoured the early initiation of pharmacotherapy alone, whereas those in Austria and Italy primarily used psychotherapy at this stage. Combination therapy was the initial treatment option for many clinicians in the Netherlands, Switzerland, France, Iceland and Germany. There may be many reasons for these differences. For example, special legislation in Italy does not allow the use of methylphenidate beyond some privileged institutions, which undoubtedly influences the prescribing habits of Italian physicians. In other countries, the limited availability of trained staff to provide psychological interventions (particularly within a paediatric setting) prompts the early use of medication. It is also important to recognise that for many but not all of the ADORE subjects, these initial data will have been gathered at the time of initial diagnosis and that many clinicians will refrain from prescribing stimulant medication at this first appointment feeling that either a further period of assessment or psychoeducation/counselling is required first. Indeed, the European guidelines for hyperkinetic disorders [41] suggest that a full assessment should in- volve more than one meeting with the child and family. Moreover, following diagnosis, medication should be initiated early for cases of severe pervasive disabling ADHD, but that an initial trial of psychological therapy is appropriate for those with less severe ADHD, with medication being reserved for those who do not respond to this treatment. The different pathways through treatment taken by the ADORE study subjects will become clearer with the longitudinal data over 2 years and will be the subject of future reports.

\section{Limitations}

There are certain limitations associated with observational studies. The non-randomised enrolment procedure and limited selection criteria increases the likelihood of treatment group bias and within- and between-group heterogeneity. Furthermore the assessments in the ADORE study are based on investigator and parental reports, and no information was collected from the child or their teachers. Although parental reports have previously been shown to be reliable $[9,11]$, the unblinded nature of the study means that post-baseline ratings by investigators and parents may be influenced by bias about treatment. Also, although all of the investigators involved in the study attended an initial training session, the large number of recruiting sites and raters did not allow for an assessment of inter-rater reliability to be made.

\section{Conclusion}

The baseline findings of the ADORE study indicate that ADHD is a disorder that is recognised and diagnosed by clinicians in Europe, and that those children diagnosed by these clinicians suffer from high symptom levels, significant impairment and poor quality of life. In this respect, they bear close resemblance to children included in previous ADHD research studies. There was a broad agreement between physicians and parents in the $10 \mathrm{Eu}-$ ropean countries on ADHD symptom severity, co-existing problems, burden of illness and quality of life, although there appear to be some differences between countries in the use of ADHD diagnostic criteria and initial treatment interventions. The longitudinal data provided by the ADORE study will determine whether these similarities and differences are sustained over the 2-year study period.

Acknowledgements The authors would like to thank the investigators and parents/carers for participating in this study. The authors also thank Lynne Poole from the Statistics Department of Eli Lilly and Company for her invaluable assistance with the statistical analysis and Deirdre Elmhirst for the editorial development of the manuscript. 


\section{References}

1. American Psychiatric Association (1994) Diagnostic and Statistical Manual of Mental Disorders, fourth edition. American Psychiatric Association, Washington

2. Anastopoulos AD, Guevremont DC, Shelton TL, DuPaul GJ (1992) Parenting stress among families of children with attention deficit hyperactivity disorder. J Abn Child Psychol 20:503-520

3. Becker A, Steinhausen HC, Baldursson G, Dalsgaard S, Lorenzo MJ, Ralston SJ, Döpfner M, Rothenberger A, and the ADORE study group (2006) Psychopathological screening of children with ADHD: Strengths and Difficulties Questionnaire in a pan-European study. Eur Child Adolesc Psychiatry 15(Suppl 1):56-62

4. Biederman J, Newcorn J, Sprich S (1991) Comorbidity of attention deficit hyperactivity disorder with conduct, depressive, anxiety, and other disorders. Am J Psychiatry 148:564-577

5. Brown TE (2005) Attention-deficit disorders and comorbidities in children, adolescents and adults. American Psychiatric Press Inc., Washington

6. Corkum P, Tannock R, Moldofsky H (1998) Sleep disturbances in children with attention-deficit/hyperactivity disorder. J Am Acad Child and Adolescent Psychiatry 37:637-646

7. Döpfner M, Steinhausen HC, Coghill D, Dalsgaard S, Poole L, Ralston SJ, Rothenberger $\mathrm{A}$ and the ADORE study group (2006) Cross-cultural reliability and validity of ADHD assessed by the ADHD Rating Scale in a pan-European study. Eur Child Adolesc Psychiatry 15(Suppl 1):46-55

8. DuPaul GJ, Power TJ, Anastopoulos AD, Reid R (1998) ADHD Rating Scale-IV: Checklists, Norms, and Clinical Interpretation. Guilford Press, New York

9. Efron D, Jarman FC, Barker MJ (1998) Child and parent perceptions of stimulant medication treatment in attention deficit hyperactivity disorder. J Paediatr Child Health 34:288-292

10. Escobar R, Soutullo CA, Hervas A, Gastaminza X, Polavieja P, Gilaberte I (2005) Worse quality of life for children with newly diagnosed attentiondeficit/hyperactivity disorder, compared with asthmatic and healthy children. Pediatrics 116:e364-e369

11. Faraone SV, Biederman J, Milberger S (1995) How reliable are maternal reports of their children's psychopathology? One-year recall of psychiatric diagnoses of ADHD children. J Am Acad Child Adolesc Psychiatry 34:1001-1008

12. Faraone SV, Tsuang MT (2001) Adult attention deficit hyperactivity disorder. Curr Psychiatry Rep 3:129-130
13. Gillberg C (1998) Hyperactivity, inattention and motor control problems: prevalence, comorbidity and background factors. Folia Phoniatrica et Logopaedica 50:107-117

14. Goodman R (1997) The Strengths and Difficulties Questionnaire: a research note. J Child Psychol Psychiatry 38: 581-586

15. Goodman R (2001) Psychometric properties of the strengths and difficulties questionnaire. J Am Acad Child Adolescent Psychiatry 40:1337-1345

16. Guy W (1976) Subject's Treatment Emergent Symptom Scale. In: Guy W (ed) Assessment Manual for Psychopharmacology. Washington, US Government Printing Office, pp 347-350

17. Jensen PS, Martin D, Cantwell DP (1997) Comorbidity in ADHD: implications for research, practice and DSM-V. J Am Acad Child Adolesc Psychiatry 36: 1065-1079

18. Johnston C, Mash EJ (2001) Families of children with attention-deficit/hyperactivity disorder: review and recommendations for future research. Clin Child Fam Psychol Rev 4:183-207

19. Kirov R, Kinkelbur J, Heipke S, Kostanecka-Endress T, Westhoff M, Cohrs S, Rüther E, Hajak G, Banaschewski T, Rothenberger A (2004) Is there a specific polysomnographic sleep pattern in children with attention deficit/hyperactivity disorder? J Sleep Res 13: 87-93

20. Kirov R, Pillar G, Rothenberger A (2004) REM-sleep changes in children with attention-deficit/hyperactivity disorder: methodologic and neurobiologic considerations. Sleep 27:1215 [letter]

21. Klassen AF, Miller A, Fine S (2004) Health-related quality of life in children and adolescents who have a diagnosis of attention-deficit/hyperactivity disorder. Pediatrics 114:e541-e547

22. Matza LS, Paramore C, Prasad M (2005) A review of the economic burden of ADHD. Cost Effectiveness and Resource Allocation 3:5

23. Matza LS, Rentz AM, Secnik K, Swensen AR, Revicki DA, Michelson D, Spencer T, Newcorn JH, Kratochvil CJ (2004) The link between health-related quality of life and clinical symptoms among children with attention-deficit hyperactivity disorder. J Devel Behav Pediatr 25:166-174
24. Michelson D, Allen AJ, Busner J, Casat C, Dunn D, Kratochvil C, Newcorn J, Sallee FR, Sangal RB, Saylor K, West S, Kelsey D, Wernicke J, Trapp NJ, Harder D (2002) Once-daily atomoxetine treatment for children and adolescents with attention-deficit hyperactivity disorder: a randomized, placebo-controlled study. Am J Psychiatry 159:1896-1901

25. Michelson D, Faries D, Wernicke J, Kelsey D, Kendrick K, Sallee FR, Spencer $\mathrm{T}$ and the Atomexetine ADHD Study Group (2001) Atomoxetine in the treatment of children and adolescents with attention-deficit/hyperactivity disorder: a randomized, placebo-controlled, dose-response study. Pediatrics 108:E83

26. MTA Cooperative Group (1999) A 14month randomized clinical trial of treatment strategies for attentiondeficit/hyperactivity disorder. The MTA Cooperative Group. Multimodal Treatment Study of Children with ADHD. Arch Gen Psychiatry 56: 1073-1086

27. Owens JA (2005) The ADHD and sleep conundrum: a review. J Devel Behav Pediatr 26:312-322

28. Perwien AR, Faries DE, Kratochvil CJ, Sumner CR, Kelsey DK, Allen AJ (2004) Improvement in health-related quality of life in children with ADHD: an analysis of placebo controlled studies of atomoxetine. J Devel Behav Pediatr 25: 264-271

29. Pliszka SR (2000) Patterns of psychiatric comorbidity with attentiondeficit/hyperactivity disorder. Child Adolesc Psychiatr Clin North Am 9: 525-540

30. Ralston SJ, Lorenzo MJ (2004) ADORE Attention-Deficit Hyperactivity Disorder Observational Research in Europe. Eur Child Adolesc Psychiatry 13(Suppl 1):36-42

31. Riley AW, Coghill D, Forrest CB, Lorenzo MJ, Ralston SJ, Spiel G and the ADORE study group (2006) Validity of the health-related quality of life assessment in the ADORE study: parent report form of the CHIP-Child Edition. Eur J Child Adolesc Psychiatry 15(Suppl 1):63-71

32. Riley AW, Forrest CB, Starfield B, Rebok GW, Robertson JA, Green BF (2004) The parent report form of the CHIP-Child Edition: reliability and validity. Med Care 42:210-220

33. Riley AW, Robertson JA, Forrest $\mathrm{CB}$, Green BF, Rebok G, Starfield B (2001) Technical Manual for the Child Health and Illness Profile - Child Edition (CHIP-CE) Parent and Child Report Forms, 1.0 edn, Johns Hopkins University, Baltimore 
34. Riley AW, Spiel G, Coghill D, Döpfner M, Falissard B, Lorenzo MJ, Preuss U, Ralston SJ and the ADORE study group (2006) The Family Strain Index (FSI). Reliability, validity and factor structure of a brief questionnaire for families of children with ADHD. Eur Child Adolesc Psychiatry 15(Suppl 1):72-78

35. Rothenberger A, Woerner W (2004) Strengths and Difficulties Questionnaire (SDQ)-evaluations and applications. Eur Child Adolesc Psychiatry 13(Suppl 2):1-2

36. Rutter M (1967) A children's behaviour questionnaire for completion by teachers: preliminary findings. J Child Psychol Psychiatry 8:1-11

37. Shaffer D, Gould MS, Brasic J, Ambrosini P, Fisher P, Bird H, Aluwahlia S (1983) A children's global assessment scale (CGAS). Arch Gen Psychiatry 40: 1228-1231
38. Stein MA (1999) Unravelling sleep problems in treated and untreated children with ADHD. J Child Adolesc Psychopharmacol 9:157-168

39. Steinhausen HC, Nøvick TS, Baldursson G, Curatolo P, Lorenzo MJ, Pereira RR, Ralston SJ, Rothenberger $\mathrm{A}$ and the ADORE study group (2006) Co-existing psychiatric problems in ADHD in the ADORE cohort. Eur Child Adolesc Psychiatry 15(Suppl 1):25-29

40. Taylor E (1998) Clinical foundations of hyperactivity research. Behav Brain Res 94:11-24
41. Taylor E, Dopfner M, Sergeant J, Asherson P, Banaschewski T Buitelaar J, Coghill D, Danckaerts M, Rothenberger A, Sonuga-Barke E, Steinhausen HC, Zuddas A, Taylor E, Dopfner M, Sergeant J, Asherson P, Banaschewski T, Buitelaar J, Coghill D, Danckaerts M, Rothenberger A, Sonuga-Barke E, Steinhausen HC, Zuddas A (2004) European clinical guidelines for hyperkinetic disorder - first upgrade. Eur Child Adolesc Psychiatry 13(Suppl 1):7-30

42. World Health Organization (1992) The ICD-10 classification of mental and behavioural disorders: clinical descriptions and diagnostic guidelines WHO, Geneva, Switzerland 